\title{
INCURVACIÓN PENEANA SECUNDARIA A ABSCESO DE CUERPO CAVERNOSO
}

\author{
D. PASCUAL REGUEIRO, A. GARCÍA DE JALÓN MARTÍNEZ, E. MALLÉN MATEO, \\ C. SANCHO SERRANO, A. BORQUE FERNANDO, L.A. RIOJA SANZ
}

Servicio de Urología. Hospital Universitario “Miguel Servet”. Zaragoza.

Actas Urol Esp. 27 (1): 55-59, 2003

\section{RESUMEN}

"INCURVACIÓN PENEANA SECUNDARIA A ABSCESO DE CUERPO CAVERNOSO"

Tras quince días de fiebre de $40^{\circ} \mathrm{C}$, sin síntomas urinarios, aparece un caso de absceso del cuerpo cavernoso. El diagnóstico se inició con la aparición de un enorme edema escrotal debido a un foco séptico en el cuerpo cavernoso izquierdo. La ECO y el TAC confirmaron el diagnóstico, siendo necesario el drenaje quirúrgico. Tras una evolución correcta, el paciente presentó una incurvación peneana con dolor y dificultad durante las relaciones sexuales, pero no aceptó ningún tratamiento.

PALABRAS CLAVE: Absceso del cuerpo cavernoso.

\section{ABSTRACT}

"PENILE DESVIATION SECUNDARY TO A CAVERNOSAL BODY ABSCESS"

A case of unilateral cavernosal body abscess appears after fifteen days of $40^{\circ} \mathrm{C}$ fever, without urological symtoms. The diagnosis started from a big scrotum aedema, related of a local septic focus in the left cavernosal body. ECO and TAC confirmed the diagnosis, and a surgical treatment was required. After a succesful evolution, the pacient presents a left penile incurvation with pain and difficulties during the sexual relations, but he did not accept any treatment.

KEY WORDS: Cavernosal body abscess.

$\mathrm{L}$ a incurvación peneana, a pesar de no constituir un problema de salud grave, motiva consultas frecuentes en las unidades de andrología, por la alteración que motiva en la vida sexual del paciente, en forma de dificultad o imposibilidad completa para la penetración, así como dolor y/o pérdida de rigidez durante el coito.

La causa que más frecuentemente se asocia a esta alteración es la incurvación secundaria a la enfermedad de la Peyronie.

Otras incurvaciones frecuentes son las secundarias a roturas traumáticas de los cuerpos cavernosos.

En la literatura también se describen incurvaciones secundarias a procesos infectivos, que afectan en forma de abscesos al pene, sobre todo en pacientes con factores que motivan cierto grado de inmunodepresión.

En este caso clínico damos a conocer una incurvación peneana motivada por una colección purulenta, que afectaba a la raíz de uno de los cuerpos cavernosos y cuyo origen inicial bien pudiera haber sido una infección perianal.

\section{CASO CLÍNICO}

Se trata de un paciente varón de sesenta años de edad, que presenta como antecedentes de interés una brucelosis, en relación con su profesión (pastor), una alergia a la penicilina y derivados, hábito tabáquico y promiscuidad sexual habitual. 
Dicho paciente ingresa en nuestro hospital por un cuadro de fiebre de tres días de evolución con picos de hasta $40^{\circ} \mathrm{C}$ y deterioro del estado general.

En una primera valoración del paciente, se evidencia una exploración general dentro de la normalidad. Las pruebas complementarias demuestran una trombopenia $(<40.000$ plaquetas) con ligera leucocitosis, con una placa de tórax normal, así como el sedimento urinario, y sin un origen definido del cuadro febril. Se realiza una ecografía abdómino-pélvica que resulta normal.

El paciente es ingresado por el Servicio de Infecciosos con el diagnóstico de fiebre de origen desconocido.

Se inicia una batería de pruebas diagnósticas que incluyen un ecocardiograma y una serie de serologías, con el único hallazgo de unos títulos ligeramente elevados a Psitacosis que fueron repetidos a los quince días sin sufrir modificación.

Entre tanto se inicia tratamiento antibiótico intravenoso combinando ciprofloxacino, tobramicina y metronidazol. A pesar de ello el paciente experimenta un empeoramiento progresivo del estado general, con astenia, anorexia, picos febriles de hasta $41^{\circ} \mathrm{C}$ y leucocitosis con desviación izquierda marcada, manteniendo un sedimento urinario con 30 leucocitos por campo de 400 aumentos y un urocultivo negativo.

Diez días después de su ingreso, el paciente comienza a presentar un edema intenso de pene y escroto, alcanzando grandes dimensiones en el plazo de dos días, motivo por el cual se nos consulta.

En una primera valoración urológica del paciente, no se constata clínica prostática, dolor lumbar, ni antecedentes de cólicos ni hematurias. No refiere dificultades miccionales, no recordando infecciones de transmisión sexual, negando la práctica de zoofilia, pero si reconociendo conducta sexual de riesgo reiterada.

$\mathrm{Al}$ tacto rectal no se aprecian colecciones pararrectales, no resulta doloroso, y la exploración prostática resulta un grado I, no flogósica y sin signos de afectación.

A nivel de genitales sólo llama la atención el gran edema escrotal, indoloro por otra parte y un hipospadias balanoprepucial.

A nivel perineal se detecta un empastamiento no muy llamativo, pero que provoca una clínica álgica intensa, aunque sin fluctuación ni crepitación, y a nivel inguinal, adenopatías reaccionales.
Ese mismo día se realiza una ecografía de vías urinarias constatando el gran edema escrotal, un ligero hidrocele reaccional y un leve aumento de tamaño de ambos epidídimos, testículos normales, un volumen prostático de $21 \mathrm{cc}$, y una vía urinaria superior sin alteraciones (Fig. 1).

Ante la persistencia de los picos febriles, a pesar del tratamiento antibiótico, y la clínica álgica, que se va acentuando, se decide la realización de un TAC abdómino pélvico, que pone de manifiesto una colección abcesificada anfractuosa, que comienza en la raíz del pene a nivel del bulbo esponjoso y dependiente del cuerpo cavernoso izquierdo, que se extiende caudalmente por detrás de la bolsa escrotal con empastamiento del tejido celular subcutáneo unido a un engrosamiento del músculo puborrectal y transverso
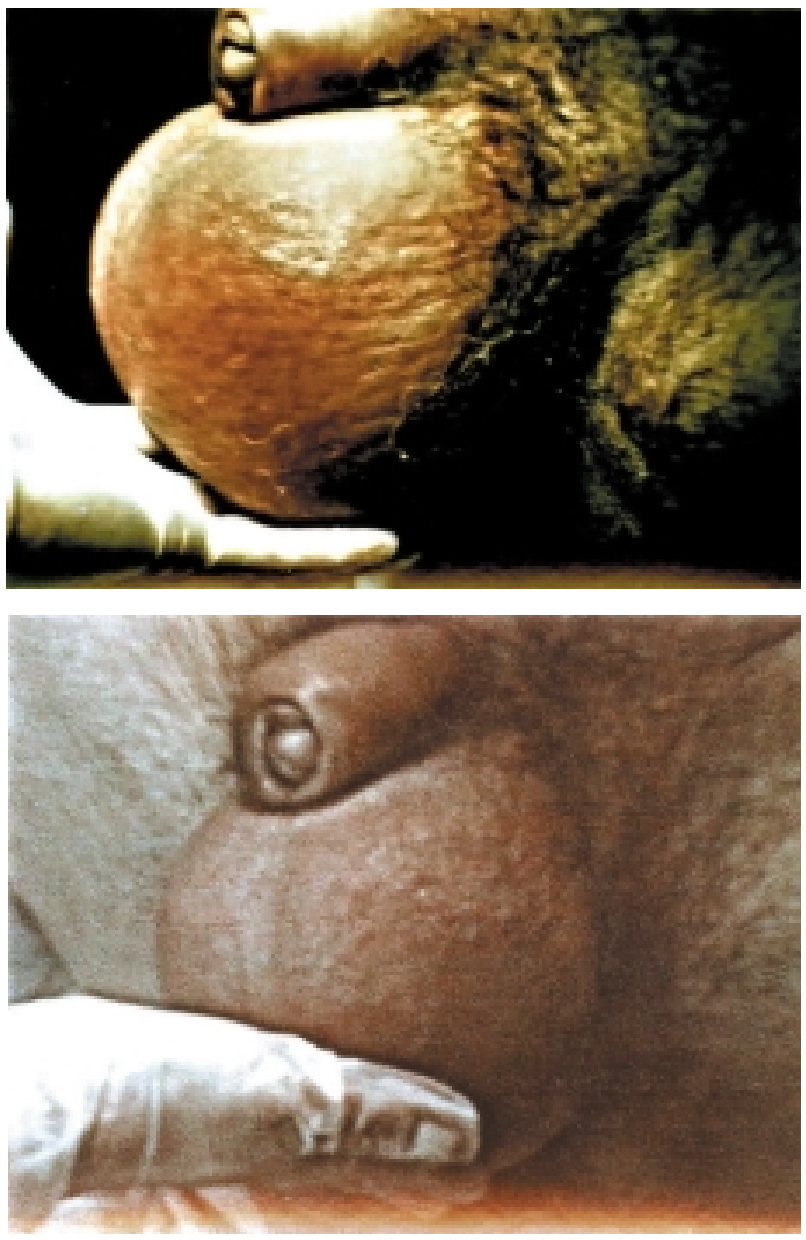

FIGURA 1. Imagen macroscópica que muestra el gran aumento de tamaño de la bolsa escrotal debido al edema reaccional. Asimismo se evidencia el edema peneano. (Mano del urólogo como referencia). 
superficial del periné con afectación de la grasa de la fosa isquiorectal izquierda. No se evidencia compromiso del canal anal, siendo la colección extraesfinteriana.

Dicho absceso, es de contornos irregulares y mide $8 \times 6 \mathrm{~cm}$. y abomba tejido subcutáneo por detrás del escroto (Fig. 2).

Con estos hallazgos se decide el drenaje quirúrgico de la mencionada colección.

La primera actuación realizada es una ecografía de partes blandas, que muestra la colección a una profundidad de $5 \mathrm{~mm}$ bajo la piel de periné. Se continúa entonces con una cistoscopia, que evidencia una uretra de calibre justo (el cistoscopio de $14 \mathrm{Ch}$ pasa con leve dificultad), de aspecto pálido, desflecado y friable, visualizándose múltiples orificios glandulares parauretrales.

No se encuentran crecimientos intraluminales, ni divertículos ni trayectos fistulosos. La próstata bilobulada no obstructiva, y una vejiga con leve trabeculación de esfuerzo con ambos orificios ureterales visibles y normales.

Se aprovecha el control endoscópico para la colocación de un catéter suprapúbico y mantener así la uretra desfuncionalizada. Así mismo, se coloca una sonda de Nelaton de $14 \mathrm{Ch}$. para tutorizar la uretra y no dañarla durante la cirugía.

Con el paciente en posición de litotomía se procede al drenaje del absceso, a través de una incisión de unos $5 \mathrm{~cm}$, longitudinal, en el rafe medio del periné, obteniéndose unos 250 cc de material purulento y maloliente. Se identifica mediante el tacto la sonda uretral, y se procede a desbridar digitalmente el absceso, que presenta dos trayectos bien diferenciados: su inicio, que diseca el cuerpo cavernoso izquierdo, proyectándose entre el músculo bulbocavernoso y el isquiocavernoso, $\mathrm{y}$ un segundo trayecto hacia fosa isquiorrectal, sin alcanzarla y dejando el recto y esfinter anal indemnes.

Se dejan tres drenajes de Penrose, dos de ellos por contra incisión, y el tercero a través de la herida, dejando cicatrizar por segunda intención.

El postoperatorio transcurre favorablemente, desapareciendo la fiebre casi por completo al día siguiente de la intervención. Se mantiene la misma pauta antibiótica inicial, así como lavados diarios de la herida con povidona yodada y agua oxigenada al $50 \%$.
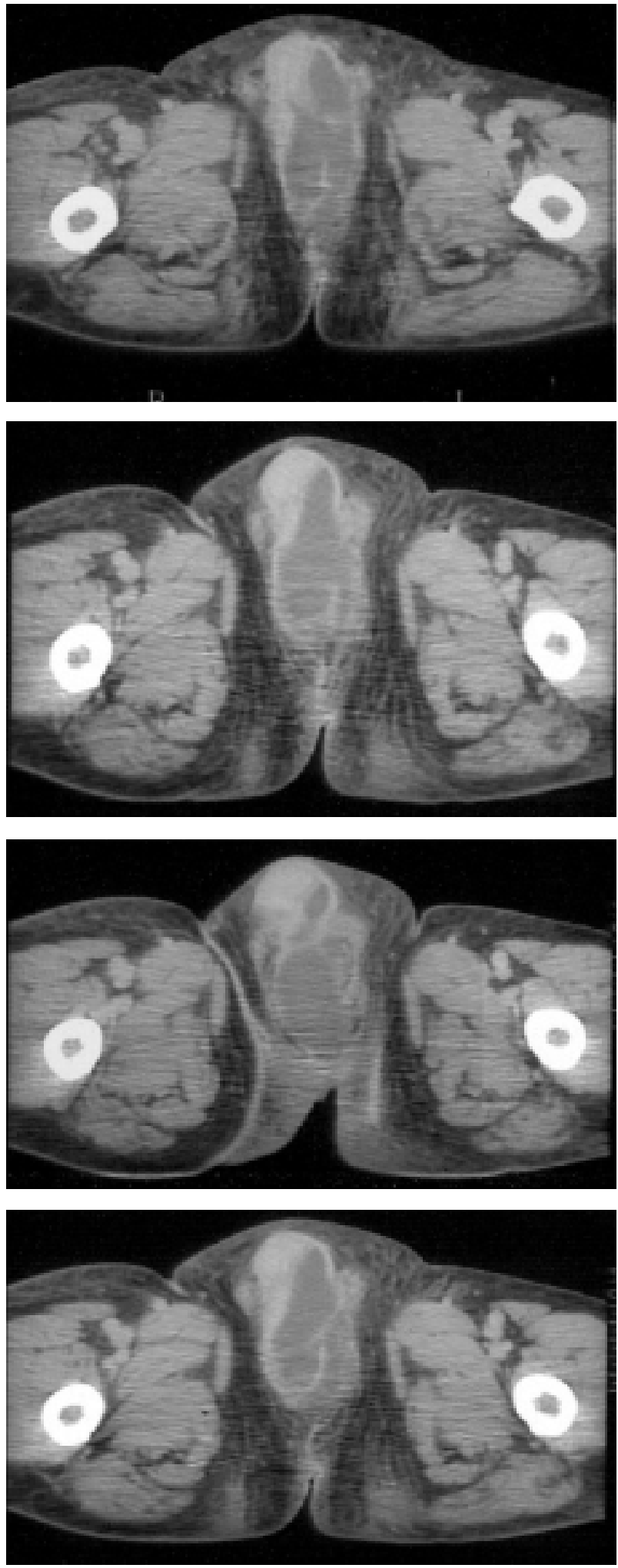

FIGURA 2. Cortes del TAC, donde se aprecia el absceso de la raiz del pene, disecando el cuerpo cavernoso izquierdo y produciendo compresión del bulbo uretral. La colección se presenta en todo momento independiente del recto y del esfinter anal. 
El cultivo microbiológico del material drenado es positivo a Enterococo spp. y a un Bacilo difterimorfo, suspendiéndose la antibioterapia parenteral, e iniciándose vía oral con Vancomicina (250 $\mathrm{mg} / 8 \mathrm{~h}$ ), según aconseja el antibiograma.

El paciente mantiene buenas diuresis por el catéter suprapúbico, desapareciendo totalmente el edema escrotal y peneano, la fiebre, y normalizándose el recuento leucocitario.

Una vez retirado el antibiótico, se realiza nuevo cultivo de orina del catéter, que resulta negativo.

Se procede al pinzado del catéter suprapúbico, consiguiendo el paciente micción espontánea y sin residuo. Se realizan uretrografias anterógradas y retrógradas encontrándose una uretra anterior arrosariada, no reflujo prostático ni a las glándulas de Cowper; no se aprecian fístulas, ni estenosis (Fig. 3).

En el control posterior en consultas, dos meses después, se constatan similares hallazgos uretrográficos, con una uretra inelástica de aspecto arrosariado y disminuida de forma global de calibre. Sigue sin apreciarse fístulas ni estrecheces evidentes, refiriendo el paciente una buena calidad miccional.
A nivel perineal la herida tiene buen aspecto, sin signos inflamatorios, habiendo cicatrizado correctamente y habiendo desaparecido por completo el edema escrotal.

El paciente sin embargo relata que desde la fase aguda ha venido notando un endurecimiento del pene en su cara lateral izquierda, así como una desviación hacia ese mismo lado de unos $20^{\circ}$.

A la exploración se evidencia una placa fibrosa en la albugínea del cuerpo cavernoso izquierdo de carácter reaccional tras el proceso inflamatorio. Ante los requerimientos del paciente se le propone una corrección de la incurvación.

Visto nuevamente en consultas sigue aquejando molestias únicamente durante la penetración.

Asímismo nos trae las autofotografías realizadas en su domicilio, donde se constata una desviación no muy importante hacia el lado izquierdo (Fig. 4).

Se plantea la corrección de la incurvación con plicatura de la túnica albugínea según la técnica de Nesbit, rechazando el paciente en el último momento la intervención.
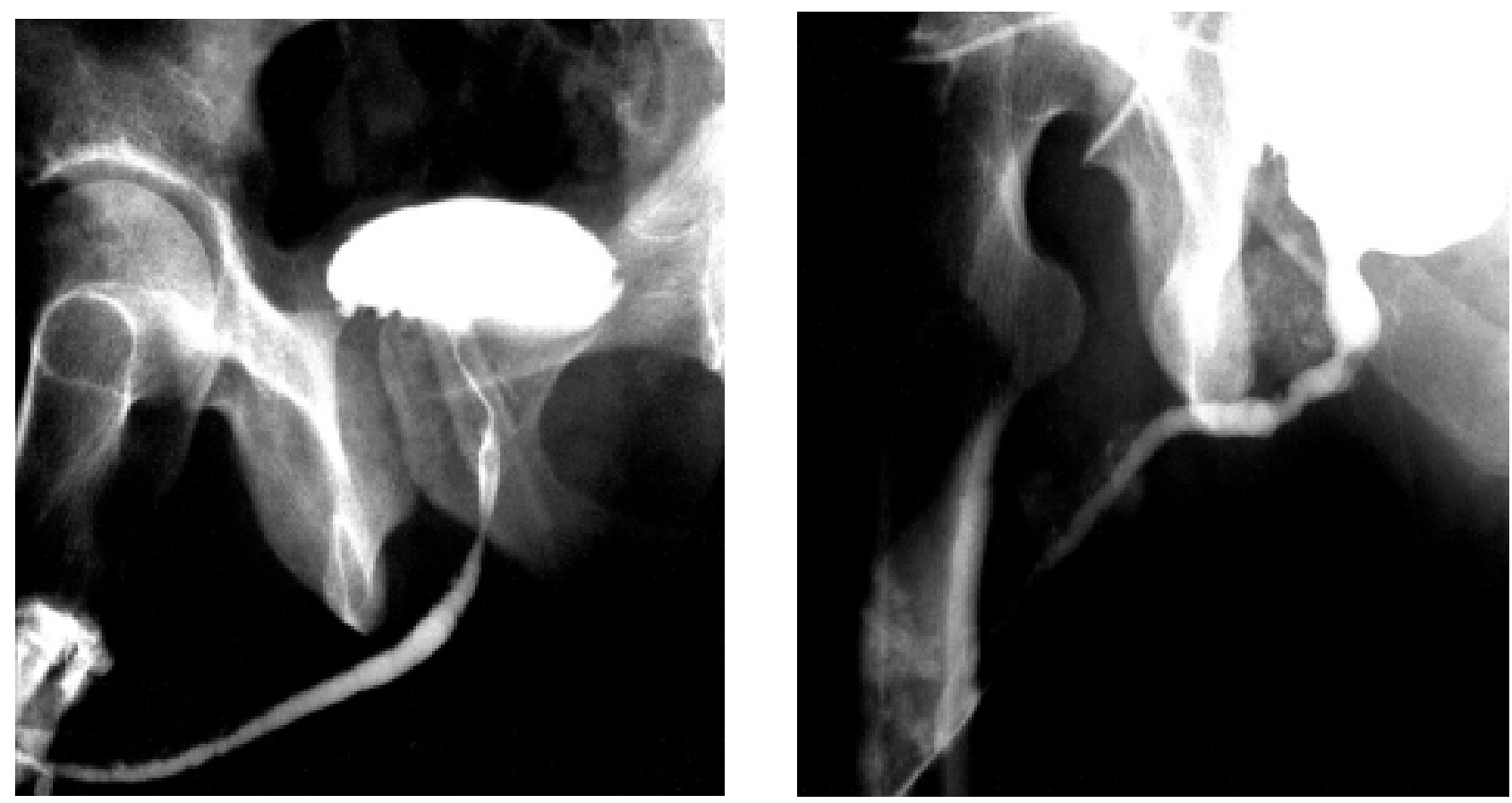

FIGURA 3. Uretrocistografia: a la izquierda imagen retrógrada, en la que se aprecia una uretra rigida de aspecto arrosariado, de mucosa irregular, pero sin signos de clara estenosis ni imágenes de divertículos. A la derecha uretrografia miccional en la que no se aprecia obstrucción prostática, no estenosis ni imágenes diverticulares. 


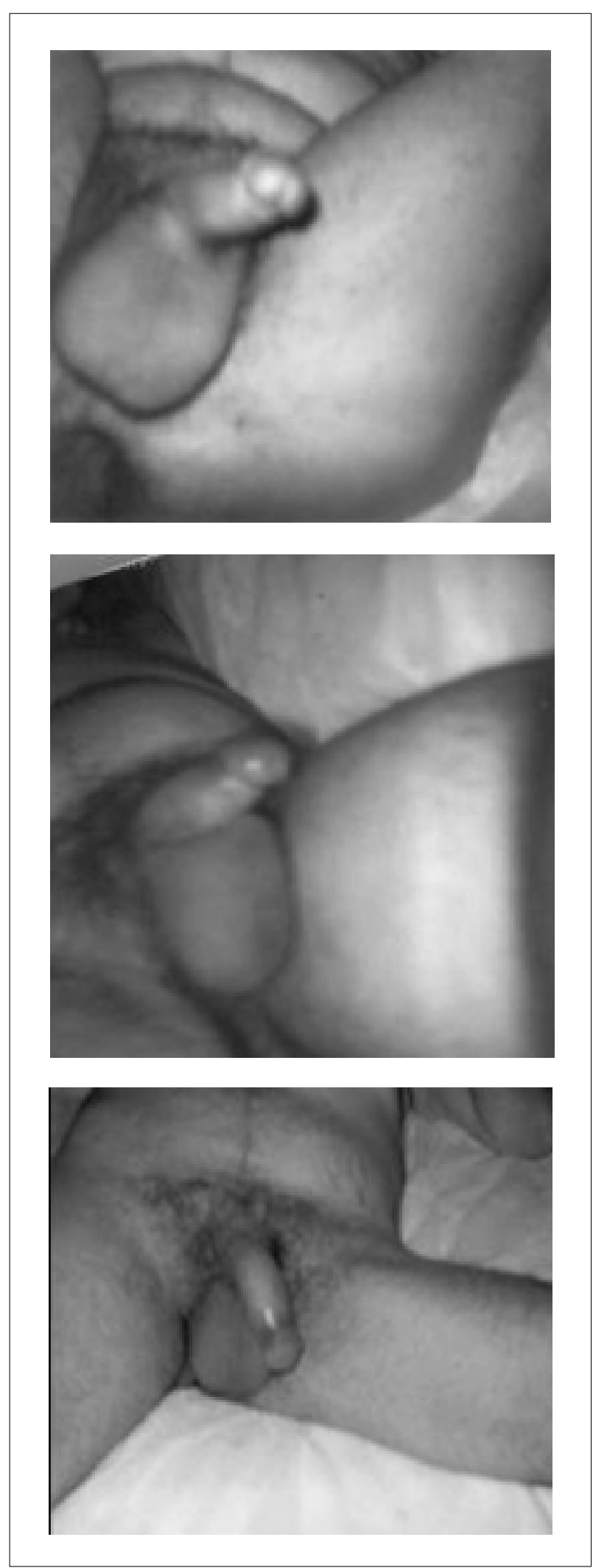

FIGURA 4. Autofotografias que demuestran incurvación peneana lateral izquierda de aproximadamente veinte grados que provocan molestia y dificultad para la penetración.

\section{REFERENCIAS}

1. KOKSAL T, KADIOGLU A, TEFEKLI A, USTA M, BESISIK A, EROL B: Spontaneous bacterial abscess of bilateral cavernosal bodies. BJU Int 1999 dec; 84 (9): 1.107-1.108.

2. FRANK I, LIEBER MM: Gas containing cavernous abscess secondary to an intra-abdominal abscess. $J$ Urol 1999 oct; 162 (4): 1.382-1.383.

3. WILDBERGER JE, WEIN BB, WOLFF JM: Abscessing cavernitis--its imaging by MRT. Rofo Fortschr Geb Rontgenstr Neuen Bildgeb Verfahr 1999 may; 170 (5): 517-519.

4. FERNÁNDEZ DURÁN AM, MARTÍN GARCÍA C, FERNÁNDEZ GÓMEZ J, JIMÉNEZ LÓPEZ-LUCENDO N, SAMPIETRO CRESPO A: Priapism secondary to a bilateral abscess of the corpora cavernosa. Actas Urol Esp 1999 jan; 23 (1): 64-66.

5. KAMEDA K, HAYASHI N, ARIMA K, YANAGAWA M, KAWAMURA J, YONEMURA S, KINBARA H: Abscess of corpus cavernosum: a case report. Hinyokika Kiyo 1998 dec; 44 (12): 893-895.

6. MURALI TR, RAJA NS: Cavernosal cold abscess: a rare cause of impotence. Br J Urol 1998 dec; 82 (6): 929-930.

7. ACKERMAN L, YAP WY, SHIRAZI P, VAN DRUNEN M: Ga-67 imaging of a penile abscess. Clin Nucl Med $1998 \mathrm{feb} ; 23$ (2): 112-113.

8. FERNÁNDEZ GÓMEZ JM, REGADERA SEJAS FJ, PÉREZ GARCÍA FJ, SAHAGUN ARGUELLO JL: Bilateral abscess of cavernous bodies. Actas Urol Esp 1997 jan; 21 (1): 75-77.

9. KROPMAN RF, DE LA FUENTE RB, VENEMA PL, VAN IMHOFF WL: Treatment of corpus cavernosum abscess by aspiration and intravenous antibiotics. $J$ Urol 1993 nov; 150 (5 Pt 1): 1.502-1.503.

10. MOSKOVITZ B, VARDI Y, PERY M, BOLKIER M, LEVIN DR: Abscess of corpus cavernosum. Urol Int 1992; 48 (4): 439-440.

11. YACHIA D, FRIEDMAN M, AUSLAENDER L: Tuberculous cold abscess of the corpus cavernosum: a case report. J Urol 1990 aug; 144 (2 Pt 1): 351-352.

12. SATER AA, VANDENDRIS M: Abscess of corpus cavernosum. J Urol 1989 apr; 141 (4): 949.

13. NIEDRACH WL, LERNER RM, LINKE CA: Penile abscess involving the corpus cavernosum: a case report. J Urol 1989 feb; 141 (2): 374-375.

14. SUBRAMANIAN S: Gonococcal urethritis with bilateral tysonitis and periurethral abscess. Sex Transm Dis 1981 apr-jun; 8 (2): 77-78.

Dr. D. Pascual Regueiro

Avda. Compromiso de Caspe, 27-29, $2^{\circ}$ A 50002 Zaragoza

(Trabajo recibido el 3 abril de 2002) 